\title{
RESULTADOS DOS ATLETAS BRASILEIROS DE GINÁSTICA ARTÍSTICA MASCULINA CONTEMPLADOS PELA BOLSA ATLETA PÓDIO
}

Pauline Peixoto Iglesias Vargas Doutoranda em Educação Física

Universidade Federal do Paraná piglesiasvargas@gmail.com

Natasha Santos-Lise

Doutora em Educação Física Universidade Estadual de Ponta Grossa natashaslise@uepg.br

Fernando Marinho Mezzadri Doutor em Educação Física Universidade Federal do Paraná mezzadri@ufpr.br

André Mendes Capraro Doutor em História

Universidade Federal do Paraná andrecapraro@gmail.com

Resumo

Objetivo do estudo: Trata-se de um estudo ${ }^{1}$ de caso com base em evidências que apresentou os resultados internacionais dos atletas de ginástica artística masculina contemplados pelo Bolsa Atleta Pódio e buscou relações com as categorias de bolsa por eles recebidas ao longo da carreira esportiva; para definir questões e hipóteses que auxiliem na avaliação do referido Programa.

Metodologia/Abordagem: A partir da análise documental identificou-se nove ginastas contemplados entre os anos de 2014 e 2020. Para realizar a coleta de dados dos resultados dos atletas, buscou-se as melhores colocações deles nas principais competições internacionais.

Originalidade/Relevância: O Programa Bolsa-Atleta é a principal política pública nacional de financiamento direto ao atleta, porém é escasso a produção científica que avalia, baseado em evidências, os resultados do Programa.

Principais resultados: Pode-se inferir que: dentre o total de nove atletas, dois não participaram de Jogos Olímpicos e/ou Campeonatos Mundiais; os resultados internacionais dos ginastas, assim como as categorias de bolsa por eles recebidas sofrem oscilações; os medalhistas olímpicos (Diego Hypólito, Arthur Zanetti e Arthur Nory) estavam recebendo o benefício da Bolsa Pódio na ocasião.

Contribuições teórico-metodológicas: Evidencia-se que os atletas da ginástica artística masculina mantiveram certa perenidade enquanto beneficiários do Programa Bolsa-Atleta. Em específico a categoria Pódio se estabelece como uma espécie de gratificação ao atleta, no entanto, pode auxiliar o atleta na conquista de bons resultados em competições internacionais.

Palavras-chave: Bolsa-atleta. Ginástica artística masculina. Governo federal. Políticas públicas. Carreira esportiva.

\section{$\underline{\text { Cite como }}$}

American Psychological Association (APA)

Vargas, P. P. I., Santos-Lise, N., Mezzadri, F. M., \& Capraro, A. M. (2022, jan./abr.). Resultados dos atletas brasileiros de ginástica artística masculina contemplados pela bolsa atleta pódio. PODIUM Sport, Leisure and Tourism Review, São Paulo, 11(1), 121-144. https://doi.org/10.5585/podium.v11i1.19564.

${ }^{1}$ Os autores declaram não haver nenhum tipo de conflitos de interesse. 


\title{
RESULTS OF BRAZILIAN MALE ARTISTIC GYMNASTICS ATHLETES CONTEMPLATED BY THE BOLSA ATLETA PÓDIO
}

\begin{abstract}
Objectives: This article is an evidence-based case study that presented the international results of male artistic gymnastics athletes contemplated by the Bolsa Atleta Pódio and sought relationships with the scholarship categories they received throughout their sports career, to define questions and hypotheses that assist in the evaluation of the referred Program.

Methodology/Approach: From the documentary analysis, nine gymnasts contemplated between the years 2014 and 2020 were identified. To collect data on the results of the gymnasts, we sought the best positions of the athletes in the main international competitions.

Originality/Relevance: Bolsa-Atleta is the main national public policy for direct funding to athletes, but the scientific production that evaluates the results of the Program, based on evidence, is low.

Main results: From this investigation, we may state that: out of a total of nine athletes, two did not participate in the Olympic Games and/or World Championships; the international results of the gymnasts, as well as the scholarship categories they were in, oscillate; the Olympic medalists (Diego Hypólito, Arthur Zanetti, and Arthur Mariano) were benefiting from the Pódio category at the time of this accomplishment.

Theoretical and methodological contributions: It is presented that the male artistic gymnastics athletes have maintained a certain permanence as beneficiaries of the Program Bolsa-Atleta. In specific, the category Podio is established as a kind of bonus to the athlete, however, it can assist the athlete in achieving good results in international competitions.
\end{abstract}

Keywords: Bolsa-atleta. Men's artistic gymnastics. Brazilian government. Public policies. Sports career.

\section{RESULTADOS DE ATLETAS BRASILEÑOS DE GIMNÁSTICA ARTÍSTICA MASCULINOS CONTEMPLADOS POR LA BOLSA ATLETA PÓDIO}

\section{Resumen}

Objetivos: Se trata de un caso de estudio basado en evidencias que presentó los resultados internacionales de deportistas masculinos de gimnasia artística contemplados por la Bolsa Atleta Pódio y buscó relacionarse con las categorías de becas que recibieron a lo largo de su carrera deportiva, definir preguntas e hipótesis que ayuden en la evaluación del Programa referido.

Metodología/Enfoque: A partir del análisis documental se identificaron nueve gimnastas contempladas entre los años 2014 y 2020. Con el fin de recolectar datos sobre los resultados de las gimnastas, se buscaron las mejores posiciones de las atletas en las principales competencias internacionales.

Originalidad/Relevancia: Bolsa-Atleta es la principal política pública nacional de financiamiento directo a los deportistas, pero hay poca producción científica que evalúe, con base en evidencias, los resultados del Programa.

Resultados principales: Se puede inferir que, de un total de nueve atletas, dos no participaron en Juegos Olímpicos y / o Campeonatos del Mundo; los resultados internacionales de las gimnastas, así como las categorías de beca que reciben, fluctúan; Los medallistas olímpicos (Diego Hypólito, Arthur Zanetti y Arthur Nory) estaban recibiendo el beneficio Bolsa-Pódio en ese momento.

Contribuciones teóricas y metodológicas: Es evidente que los deportistas masculinos de gimnasia artística mantuvieron una cierta perpetuidad como beneficiarios del Programa. La Bolsa Atleta Pódio se establece como una especie de bono para el deportista, sin embargo, puede ayudar al deportista a lograr buenos resultados en competiciones internacionales.

Palabras clave: Bolsa-atleta. Gimnasia artística masculina. Gobierno federal. Políticas públicas. Carrera deportiva. 


\section{Introdução}

Uma das principais ações das políticas públicas para o desenvolvimento do esporte no Brasil, o Programa Bolsa-Atleta (PBA), desde sua criação, em 2005, vem beneficiando atletas brasileiros com recursos federais (Brasil, 2004; Mezzadri, Moraes, Figuêroa, \& Starepravo, 2015; Moraes, Mezzadri, Santos, Camargo, \& Figuerôa, 2015). Um dos principais diferenciais do PBA é o direcionamento do recurso diretamente ao atleta, sem intermediários, com a intenção de assegurar condições mínimas para o atleta treinar e competir (Camargo \& Mezzadri, 2017; Teixeira, Matias, Carneiro, \& Mascarenhas, 2017). Inicialmente, foram constituídas quatro categorias de bolsas, a saber: Olímpica/Paraolímpica; Internacional; Nacional; e Estudantil (Corrêa, Moraes, Mezzadri, \& Cavichiolli, 2014). Em 2013, especificamente a partir da Lei 12.395/2011, foram incluídas as categorias Base e Pódio. Essa última trata-se da mais alta categoria do PBA, a qual atualmente oferece bolsas de $\mathrm{R} \$ 5.000,00$ a $\mathrm{R} \$ 15.000,00$ mensais aos contemplados, a depender de sua posição no ranking mundial (Brasil, 2017).

A categoria Pódio, como bem alerta Silva, Silvestre e Silva (2020), foi resultado das ações do Programa Brasil Medalha (PBM), o qual tinha por objetivo impulsionar o país para estar entre os dez mais bem colocados no quadro geral de medalhas nos Jogos Olímpicos e quinto lugar nos Jogos Paralímpicos, ambos realizados em território nacional (Rio 2016). Por isso, é destinada aos atletas de modalidades individuais olímpicas e paralímpicas que estejam ranqueados entre os 20 primeiros na respectiva federação internacional, seja em prova específica ou não. No entanto, tal fato não garante o recebimento da bolsa. Os critérios para o recebimento são definidos em conjunto pelo então Ministério do Esporte $^{2}$, Comitê Olímpico do Brasil (COB) ou Comitê Paralímpico Brasileiro (CPB) e a respectiva entidade esportiva nacional (Brasil, 2011). A referida Lei esclarece que o Programa Bolsa Atleta Pódio ${ }^{3}$ (PBAP) é destinado a "melhorar o resultado esportivo de atletas brasileiros em competições internacionais". Para tanto, o texto reforça critérios para que o atleta esteja apto a pleitear a categoria Pódio, dentro do PBA, são eles: estar em plena atividade esportiva; ser vinculado a entidade nacional responsável pelo esporte; declarar patrocínios provenientes de instituições públicas ou privadas; ser indicado a partir do encontro entre $\mathrm{COB} / \mathrm{CPB}$ em conjunto com a entidade mantedora do esporte nacional; e encaminhar o plano esportivo individual para o órgão nacional (Brasil, 2011).

\footnotetext{
Atualmente Secretaria Especial do Esporte, Ministério da Cidadania.

${ }^{3}$ Nas leis e documentos relacionados à Bolsa-Atleta, o termo se escreve com hífen. Todavia, ao se referir à categoria Bolsa Atleta Pódio, esta é escrita sem hífen. Optou-se por manter a grafia original.
} 
Dentre as modalidades contempladas pelo PBAP destaca-se a ginástica artística masculina (GAM). O estudo de Oliveira e Bortoleto (2012) indicou o crescimento da modalidade no país a partir do PBA. A pesquisa dos referidos autores observou dados da modalidade até o ano de 2011 e já apontava para o protagonismo dos ginastas brasileiros. Em estudo mais recente, Teixeira et al. (2017) apresentaram os resultados do Brasil nos Jogos Olímpicos de Pequim (2008), Londres (2012) e Rio de Janeiro (2016). É perceptível que a GAM apresentou desenvolvimento significativo, visto que até o ano de 2008 não havia conquistado medalha olímpica. Nos Jogos Olímpicos de Londres, em 2012, a modalidade alcançou a inédita medalha de ouro nas argolas com Arthur Zanetti. Nos Jogos do Rio de Janeiro, em 2016, os ginastas obtiveram três medalhas, sendo: duas de prata, uma com Arthur Zanetti nas argolas e outra com Diego Hypólito no solo, além de uma de bronze, com Arthur Nory na prova de solo (Federação Internacional de Ginástica, 2016).

Tendo em vista as conquistas dos ginastas brasileiros, em especial, nas duas últimas edições de Jogos Olímpicos, nos anos de 2012 e 2016, assim como o potencial do PBA, que de certa forma, vários autores (Anunciação et al., 2017; Corrêa et al., 2014; Mezzadri et al., 2015; Moraes, Mezzadri, Figueroa, \& Starepravo, 2016; Ordenhas \& Cavichiolli, 2016; Reis \& Capraro, 2020; Teixeira et al., 2017) vêm destacando sobre a sua importância para a formação de atletas em âmbito nacional, o presente estudo ${ }^{4}$ tem por objetivo apresentar os resultados internacionais dos atletas da GAM contemplados pelo PBAP e buscar relações com as categorias de bolsa por eles recebidas ao longo da carreira esportiva; para, então, definir questões e hipóteses que auxiliem na avaliação do PBA.

Tal inquietação surgiu não apenas pelo crescimento da modalidade em questão, como também no que se refere à perenidade dos atletas beneficiados pelo PBA. Isto é, com base nos resultados esportivos ao longo da carreira, os atletas da GAM melhoraram o desempenho concomitantemente a uma escalada nas categorias de bolsa? Ou se tornaram beneficiários apenas ao atingir as condições exigidas pelo PBAP?

A hipótese desta pesquisa foi a de que há uma perenidade dos atletas de alto rendimento no PBA. Tal possibilidade repousa na escassa presença de valor mercadológico das modalidades esportivas no Brasil; o que demanda intervenção Estatal, salvos um ou outro patrocínio que variam entre os diferentes esportes. ${ }^{4}$ O presente trabalho foi realizado com apoio da Coordenação de Aperfeiçoamento de Pessoal de Nível Superior - Brasil (CAPES) - Código de Financiamento 
Embora a produção científica acerca de políticas públicas para o esporte esteja em crescimento, tanto de forma qualitativa, quanto quantitativa ainda são poucas as investigações que buscam avaliar as políticas esportivas (Canan, Starepravo, \& Athayde, 2017; Reis \& Capraro, 2020; Silva, Silvestre, \& Amaral, 2020), especialmente no que tange ao principal programa federal de incentivo aos atletas brasileiros - o PBA. Sendo essa avaliação fundamental no sentido de contribuir não apenas para o aprimoramento da política pública esportiva, mas também para nortear as tomadas de decisões do governo federal, portanto de grande valia para o Estado e, por conseguinte, para a sociedade (Silva, Silvestre, \& Silva, 2020).

No que se refere às políticas públicas de esporte e lazer, conta-se já com alguns trabalhos que abarcam um profícuo levantamento bibliográfico, como as pesquisas de Starepravo (2011) e Godoy (2013), por exemplo. A partir das constatações apresentadas nos referidos trabalhos, bem como na busca de produções específicas da avaliação das políticas públicas de esporte, poucos são os trabalhos que se propõem a este fim, como os textos de Silva, Silvestre e Silva (2020) e Camargo (2020). Por este motivo, apresenta-se a seguir o referencial teórico que ancorou a investigação proposta, pautada no enquadramento teórico específico da avaliação das ações esportivas.

\section{Estudo de caso exploratório com base em evidências}

A partir da relação entre as categorias do PBA, buscou-se respaldo teórico nos referenciais de avaliação da política pública a fim de investigar a existência de uma perenidade. A avaliação tem sido considerada por muitos estudos (Brouwers, Sotiriadou, \& De Bosscher, 2015; Cavill, Foster, Oja, \& Martin, 2006; Chen, 2018; Coalter, 2017; Lindsey \& Bacon, 2016) uma fase imprescindível no ciclo político (Dye, 1972; Frey, 2000), sobretudo no momento de tomada de decisão, por possibilitar aos policy-makers uma perspectiva mais direcionada quanto ao impacto de determinada ação. Junto a tal aspecto, tem se revelado - já desde a década de 1990 - a emergência de políticas baseadas em evidências, as quais permitem que os policymakers construam intervenções pertinentes a um público-alvo específico.

Segundo Shushu Chen (2018), até o ano de 2014 foram levantadas 23 abordagens sobre avaliação da gestão pública. O ponto crucial, que, inclusive, é o foco de Chen (2018), se refere a qual a abordagem de escolha no momento de avaliar uma política ou programa esportivos.

Optou-se por centralizar esforços, especificamente, na análise do PBA, que consiste na maior política esportiva brasileira no contexto atual (Camargo, Santos, Oliveira, Quaranta, \& 
Mezzadri, 2020). Ao consultar os sítios de internet (SNEAR, 2021), observou-se apenas a existência de prestações de contas que contemplam o número de bolsas, o montante financeiro e a quantidade de atletas beneficiados. É perceptível a escassez de uma avaliação acerca do impacto que essas bolsas podem gerar no meio esportivo do país, principalmente, ao longo do período de sua implementação (Reis \& Capraro, 2020).

Diante dessa lacuna observada na avaliação das políticas públicas de esporte no Brasil, intenta-se, aqui, utilizar um referencial metodológico (Funnell \& Rogers, 2011; Newcome, Hatry, \& Wholey, 2015), a fim de definir questões e hipóteses que possam conduzir a uma posterior construção de uma teoria da mudança, aplicada ao PBA.

A referida conjunção se pauta em três combinações teóricas, entendidas como complementares para uma compreensão prévia do funcionamento da política em questão. Primeiramente, buscou-se amparar os instrumentos de coleta de dados (o "road map"), sob a perspectiva de um estudo de caso exploratório e descritivo (Martinson \& O’Brien, 2015), cujo propósito é, essencialmente, definir questões e hipóteses para estudos subsequentes. A partir de revisão de documentos, apresentar considerações preliminares da política estudada. Assim, a delimitação centrou-se na análise dos contemplados pelo PBAP, na GAM, entre os anos de 2014 e 2020 buscando dados quanto a outras bolsas recebidas por esses atletas ao longo de sua trajetória, bem como seus respectivos resultados esportivos.

Somadas a esses elementos, estão algumas prerrogativas da avaliação exploratória (Wholey, 2015), a qual se direciona, via de regra, a programas amplos, descentralizados, e com critérios de avaliação pouco claros. Ora, embora o PBAP faça parte de um Programa que, apesar de bastante amplo, é extremamente centralizado na figura do governo federal brasileiro (Secretaria Especial de Esporte), os parâmetros de avaliação se apresentam de forma subjetiva, coadunados a intenções e metas pouco claras. Assim, o prisma da avaliação exploratória se torna útil na medida em que permite pensar o design do Programa. O PBA está em andamento desde 2005, todavia não houve um estudo exploratório antes da definição de como atuaria tal política. Wholey $(2015$, p. 88) aponta que este tipo de investigação “[...] produzirá os resultados da avaliação e ajudará o avaliador e os demais a identificar as prioridades para os futuros estudos de avaliação [...]" (tradução nossa). Nesse sentido, a presente pesquisa faz parte de um estudo maior, buscando lançar questões, inferências não generalizantes e hipóteses para se pensar a construção de um modelo lógico, que auxilie na teoria da mudança do PBA. Portanto, dentro da avaliação exploratória, identificou-se a evaluability assessment, que se aproxima em muito desta perspectiva, já que este tipo de análise aponta a extensão com que os programas 
estão (ou não) prontos para futura avaliação “útil”, que possa ser utilizada pelos stakeholders centrais (no caso, os coordenadores do PBA, o secretário de alto rendimento e mesmo o atleta beneficiado).

Por fim, junto às noções de estudo de caso e de avaliação exploratória, buscou-se trazer a revisão sistemática como condutora da evidência à política (Pawson, 2006). A chave da revisão sistemática está no feedback loop, isto é, com base em evidências é possível analisar o andamento do programa para, então, retomar e corrigir problemas (inclusive critérios de avaliação), que estão relacionados à implementação da política. No caso, o PBAP já está em execução e as evidências utilizadas aqui se referem à GAM, enfatizando-se resultados esportivos.

\section{Aspectos metodológicos}

Tomando os parâmetros acima elencados como pressupostos da pesquisa, foi realizado o levantamento dos atletas da modalidade de GAM contemplados pelo PBAP em todas as portarias desde seu início (2014-2020), por meio das listas de atletas contemplados divulgadas pelo governo federal e publicadas no Diário Oficial da União (2021).

Portanto, a análise documental observou os seguintes documentos: Portaria $\mathrm{n}^{\circ} 237$, de 9 de setembro de 2013; Portaria $n^{\circ} 130$, de 4 de junho de 2014; Portaria $n^{\circ} 281$, de 21 de novembro de 2014; Portaria ${ }^{\circ}$ 268, de 21 de setembro de 2015; Portaria $n^{\circ} 56$, de 4 de março de 2016; Portaria n ${ }^{\circ}$ 157, de 25 de maio de 2017; Portaria $n^{\circ}$ 01, de 03 de abril de 2018; Portaria $\mathrm{n}^{\circ} 250$, de 9 de agosto de 2018; Portaria $\mathrm{n}^{\circ}$ 380, de 28 de dezembro de 2018; Portaria $\mathrm{n}^{\circ} 2.257$, de 29 de novembro de 2019; $\mathrm{n}^{\circ} 01$, de 12 de julho de 2019: portaria $\mathrm{n}^{\mathrm{o}} 505$, de 09 de outubro de 2020.

Sendo assim, foram catalogados em planilha eletrônica todos os atletas de GAM contemplados nas portarias supracitadas, e, posteriormente, foram inseridas as demais bolsas do PBA recebidas por eles. Tais dados foram coletados a partir do banco de dados do Instituto de Pesquisa Inteligência Esportiva ${ }^{5}$, o qual apresenta informações sobre as bolsas, seus respectivos valores e os atletas brasileiros contemplados, desde o ano de 2005.

Para realizar a análise retrospectiva dos resultados obtidos pelos atletas da modalidade, realizou-se a busca das melhores colocações dos ginastas nas principais competições internacionais por meio do site da entidade mantenedora da modalidade, Federação

\footnotetext{
${ }^{5}$ Para saber mais, acesse: http://www.inteligenciaesportiva.ufpr.br/site/
} 
Internacional de Ginástica (FIG) ${ }^{6}$, a qual apresenta os dados individualmente. Anualmente, a FIG promove o Campeonato Mundial (CM), exceto nos anos em que ocorrem os Jogos Olímpicos (JO), além de etapas de Copa do Mundo (Schiavon, 2009).

Para a atribuição das bolsas da categoria Pódio, apenas os resultados conquistados em CM e JO são analisados no momento do pleito. Pois, de acordo com a Portaria $\mathrm{n}^{\circ} 76$ de 15 de março de 2017, eventos equivalentes a CM e JO somente serão considerados em caso de não acontecer nenhum destes no referido ano (Brasil, 2017). Portanto, nesta análise foram considerados apenas os resultados em CM e JO disponibilizados pela FIG. Vale destacar que foram considerados os melhores resultados em provas individuais, ou seja, nos aparelhos específicos da GAM (solo; cavalo com alças; argolas; salto paralela; e barra fixa) e na competição individual geral (somatória de todas as provas). Tais dados foram inseridos na planilha eletrônica, os quais serão apresentados na próxima seção.

Por fim, a análise de dados se deu de maneira descritiva, objetivando uma avaliação exploratória (Wholey, 2015) dos dados obtidos, referentes aos bolsistas em questão. Conforme apontado no subitem anterior, optou-se por essa descrição de cunho mais exploratório, tendo em vista que se trata de um programa amplo, sem critérios de avaliação definidos. Entende-se que essa descrição dos dados é fundamental para uma análise mais profunda do PBAP.

\section{Resultados}

O PBAP teve sua primeira portaria publicada em 2013, mas somente a partir de 2014 atletas de GAM foram contemplados por esta categoria de bolsa. Desta forma, dentre os anos de 2014 e 2020, constataram-se que nove atletas da modalidade receberam a bolsa do PBAP, sendo que todos foram contemplados com outras categorias de bolsa em anos anteriores, conforme elucidado no Quadro 1 a seguir:

\footnotetext{
${ }^{6}$ https://www.gymnastics.sport/site/events/searchresults.php
} 
Vargas, P. P. I., Santos-Lise, N., Mezzadri, F. M., \& Capraro, A. M. (2022, jan./abr.). Resultados dos atletas brasileiros de ginástica artística masculina contemplados pela bolsa atleta pódio

\section{Quadro 1.}

Atletas de GAM Contemplados Pela Bolsa Atleta Pódio (2014-2020) e Resultados

\begin{tabular}{|c|c|c|c|}
\hline Nome do atleta & Ano & Modalidades de bolsa & $\begin{array}{c}\text { Principal resultado } \\
\text { em JO e CM }\end{array}$ \\
\hline \multirow{6}{*}{ Ângelo Assumpção } & 2011 & Bolsa-Atleta Internacional & \\
\hline & 2012 & Bolsa-Atleta Internacional & \\
\hline & 2014 & Bolsa-Atleta Internacional & \\
\hline & 2015 & Bolsa-Atleta Internacional & \\
\hline & 2016 & Bolsa Atleta Pódio & \\
\hline & 2018 & Bolsa-Atleta Nacional & \\
\hline \multirow{13}{*}{ Arthur Zanetti } & 2008 & Bolsa-Atleta Internacional & \\
\hline & 2009 & Bolsa-Atleta Internacional & $4^{\circ}$ lugar $-\mathrm{CM}$ \\
\hline & 2010 & & \\
\hline & 2011 & Bolsa-Atleta Internacional & $2^{\circ}$ lugar $-\mathrm{CM}$ \\
\hline & 2012 & Bolsa-Atleta Internacional & $1^{\circ}$ lugar - JO \\
\hline & 2013 & Bolsa-Atleta Olímpica & $1^{\circ}$ lugar $-\mathrm{CM}$ \\
\hline & 2014 & Bolsa Atleta Pódio & $2^{\circ}$ lugar - CM \\
\hline & 2015 & Bolsa Atleta Pódio & $9^{\circ}$ lugar - CM \\
\hline & 2016 & Bolsa Atleta Pódio & $2^{\circ}$ lugar - JO \\
\hline & 2017 & Bolsa Atleta Pódio & $7^{\circ}$ lugar - CM \\
\hline & 2018 & Bolsa Atleta Pódio & $2^{\circ}$ lugar $-\mathrm{CM}$ \\
\hline & 2019 & Bolsa Atleta Pódio & $5^{\circ}$ lugar $-\mathrm{CM}$ \\
\hline & 2020 & Bolsa Atleta Pódio & \\
\hline \multirow{12}{*}{ Arthur Nory } & 2009 & Bolsa-Atleta Internacional & \\
\hline & 2010 & & \\
\hline & 2011 & Bolsa-Atleta Internacional & \\
\hline & 2012 & Bolsa-Atleta Internacional & \\
\hline & 2013 & & $17^{\circ}$ lugar - CM \\
\hline & 2014 & Bolsa Atleta Pódio & $18^{\circ}$ lugar - CM \\
\hline & 2015 & Bolsa Atleta Pódio & $4^{\circ}$ lugar - CM \\
\hline & 2016 & Bolsa Atleta Pódio & $3^{\circ}$ lugar - JO \\
\hline & 2017 & Bolsa Atleta Pódio & $12^{\circ}$ lugar - CM \\
\hline & 2018 & Bolsa Atleta Pódio & $27^{\circ}$ lugar - CM \\
\hline & 2019 & Bolsa Atleta Pódio & $1^{\circ}$ lugar- $\mathrm{CM}$ \\
\hline & 2020 & Bolsa Atleta Pódio & \\
\hline \multirow{8}{*}{ Caio Souza } & 2008 & Bolsa-Atleta Nacional & \\
\hline & 2009 & Bolsa-Atleta Nacional & \\
\hline & 2010 & & \\
\hline & 2011 & Bolsa-Atleta Nacional & \\
\hline & 2012 & Bolsa-Atleta Nacional & \\
\hline & 2013 & Bolsa-Atleta Internacional & \\
\hline & 2014 & & \\
\hline & 2015 & Bolsa-Atleta Internacional & $34^{\circ}$ lugar - CM \\
\hline
\end{tabular}


Vargas, P. P. I., Santos-Lise, N., Mezzadri, F. M., \& Capraro, A. M. (2022, jan./abr.). Resultados dos atletas brasileiros de ginástica artística masculina contemplados pela bolsa atleta pódio

\begin{tabular}{|c|c|c|c|}
\hline Nome do atleta & Ano & Modalidades de bolsa & $\begin{array}{c}\text { Principal resultado } \\
\text { em JO e CM }\end{array}$ \\
\hline & 2016 & Bolsa Atleta Pódio & \\
\hline & 2017 & Bolsa-Atleta Internacional & $15^{\circ}$ geral - CM \\
\hline & 2018 & Bolsa Atleta Pódio & $8^{\circ}$ lugar - CM \\
\hline & 2019 & Bolsa Atleta Pódio & $13^{\circ}$ lugar - CM \\
\hline & 2020 & Bolsa Atleta Pódio & \\
\hline \multirow{18}{*}{ Diego Hypólito } & 2002 & & $5^{\circ}$ lugar - CM \\
\hline & 2003 & & $4^{\circ}$ lugar - CM \\
\hline & 2005 & & $1^{\circ}$ lugar - CM \\
\hline & 2006 & & $2^{\circ}$ lugar - CM \\
\hline & 2007 & & $1^{\circ}$ lugar - CM \\
\hline & 2008 & & $6^{\circ}$ lugar - JO \\
\hline & 2009 & & $9^{\circ}$ lugar - CM \\
\hline & 2010 & & \\
\hline & 2011 & Bolsa-Atleta Olímpica & $3^{\circ}$ lugar - CM \\
\hline & 2012 & Bolsa-Atleta Olímpica & $59^{\circ}$ lugar - JO \\
\hline & 2013 & Bolsa-Atleta Olímpica & $5^{\circ}$ lugar - CM \\
\hline & 2014 & Bolsa Atleta Pódio & $3^{\circ}$ lugar - CM \\
\hline & 2015 & Bolsa Atleta Pódio & \\
\hline & 2016 & & $2^{\circ}$ lugar - JO \\
\hline & 2017 & Bolsa Atleta Pódio & \\
\hline & 2018 & Bolsa-Atleta Olímpica & \\
\hline & 2019 & & \\
\hline & 2020 & & \\
\hline \multirow{12}{*}{ Francisco Barretto Jr. } & 2007 & Bolsa-Atleta Internacional & \\
\hline & 2010 & & $69^{\circ}$ lugar - CM \\
\hline & 2011 & Bolsa-Atleta Internacional & $39^{\circ}$ lugar - CM \\
\hline & 2012 & Bolsa-Atleta Internacional & \\
\hline & 2013 & & $22^{\circ}$ lugar - CM \\
\hline & 2014 & & $37^{\circ}$ lugar - CM \\
\hline & 2015 & Bolsa Atleta Pódio & $32^{\circ}$ lugar - CM \\
\hline & 2016 & & $5^{\circ}$ lugar - JO \\
\hline & 2017 & Bolsa Atleta Pódio & \\
\hline & 2018 & Bolsa Atleta Pódio & $11^{\circ}$ lugar - CM \\
\hline & 2019 & Bolsa Atleta Pódio & $21^{\circ}$ lugar - CM \\
\hline & 2020 & Bolsa Atleta Pódio & \\
\hline \multirow{3}{*}{ Henrique Flores } & 2013 & Bolsa-Atleta Internacional & \\
\hline & 2015 & Bolsa Atleta Pódio & \\
\hline & 2017 & Bolsa Atleta Pódio & \\
\hline \multirow{5}{*}{ Petrix Barbosa } & 2005 & Bolsa-Atleta Estudantil & \\
\hline & 2006 & Bolsa-Atleta Nacional & \\
\hline & 2007 & Bolsa-Atleta Nacional & \\
\hline & 2008 & Bolsa-Atleta Internacional & \\
\hline & 2009 & Bolsa-Atleta Internacional & \\
\hline
\end{tabular}


Vargas, P. P. I., Santos-Lise, N., Mezzadri, F. M., \& Capraro, A. M. (2022, jan./abr.). Resultados dos atletas brasileiros de ginástica artística masculina contemplados pela bolsa atleta pódio

\begin{tabular}{|c|c|c|c|}
\hline Nome do atleta & Ano & Modalidades de bolsa & $\begin{array}{c}\text { Principal resultado } \\
\text { em JO e CM }\end{array}$ \\
\hline & 2010 & Bolsa-Atleta Internacional & \\
\hline & 2011 & Bolsa-Atleta Nacional & $52^{\circ}$ lugar - $\mathrm{CM}$ \\
\hline & 2012 & Bolsa-Atleta Internacional & \\
\hline & 2013 & Bolsa-Atleta Internacional & \\
\hline & 2014 & Bolsa-Atleta Internacional & \\
\hline & 2015 & Bolsa Atleta Pódio & \\
\hline \multirow{9}{*}{ Sérgio Sasaki Jr. } & 2008 & Bolsa-Atleta Nacional & \\
\hline & 2009 & & $19^{\circ}$ lugar - CM \\
\hline & 2010 & & $23^{\circ}$ lugar - CM \\
\hline & 2011 & Bolsa-Atleta Internacional & $37^{\circ}$ lugar - CM \\
\hline & 2012 & & $10^{\circ}$ lugar - JO \\
\hline & 2013 & Bolsa-Atleta Olímpica & $5^{\circ}$ lugar - CM \\
\hline & 2014 & Bolsa Atleta Pódio & $5^{\circ}$ lugar - CM \\
\hline & 2015 & Bolsa Atleta Pódio & \\
\hline & 2016 & & $9^{\circ}$ lugar - JO \\
\hline
\end{tabular}

Fonte: Os autores (2021).

A seguir, foram descritos os resultados individuais dos ginastas, assim como a categoria de bolsa recebida ao longo da carreira esportiva. Os atletas foram apresentados em ordem alfabética.

Ao analisar as participações internacionais do atleta Ângelo Assumpção constata-se que apesar de ter sido contemplado pelo PBAP, no ano de 2016, o atleta não participou de JO ou CM da modalidade. Por esse motivo os seus resultados não foram apresentados no Quadro 1. Possivelmente, os resultados em duas etapas de Copa do Mundo, nos anos de 2015 e 2016, foram usados para qualificá-lo ao recebimento da principal bolsa do PBA. Em especial, destacase que Ângelo Assumpção foi campeão da prova de salto na Copa do Mundo de São Paulo (SP) em 2015. No entanto, naquele ano os atletas brasileiros participaram do $\mathrm{CM}^{7}$ da modalidade. No ano seguinte, o atleta participou de outras duas etapas de Copa do Mundo e esteve presente em três finais por aparelho na etapa de Cottbus (Alemanha). Desde então, não registrou mais participações nos principais eventos internacionais da modalidade. Vale lembrar que Ângelo Assumpção foi contemplado anteriormente pela categoria Internacional do PBA, nos anos de 2011, 2012, 2014 e 2015.

O campeão olímpico nas argolas (2012) Arthur Zanetti recebeu a categoria Internacional do PBA desde 2008 até o ano de 2013, quando foi contemplado com a categoria Olímpica.

${ }^{7}$ Em 2015, o Brasil participou da competição representado por: Arthur Nory, Arthur Zanetti, Caio Souza, Francisco Barretto Jr., Lucas Bitencourt e Péricles Silva (FIG, 2015). 
Depois disso o atleta passou a ser contemplado pelo PBAP. O único ano em que não participou do PBA, 2010, foi o mesmo em que ficou de fora do CM da modalidade. Arthur Zanetti foi quarto lugar no CM de 2009 nas argolas, aparelho em que é especialista. Em 2011 foi vicecampeão mundial nessa prova e, no ano seguinte, o atleta consagrou-se campeão nos JO de Londres. Após essa grande conquista para a GAM do Brasil, o atleta manteve o excelente desempenho no CM de 2013 com a conquista do título das argolas. No CM de 2014, Arthur Zanetti foi vice-campeão na prova de argolas. No ano subsequente, o atleta passou da segunda colocação para o nono lugar na disputa de argolas no mundial. Nos JO do Rio de Janeiro, em 2016, o atleta voltou a comparecer no pódio, ao conquistar a prata na sua especialidade. Após os JO do Rio de Janeiro os resultados de Arthur Zanetti oscilaram na prova de sua especialidade, mas sempre entre os finalistas do aparelho nos CMs, a saber: sétimo lugar; vice-campeão; e quinto lugar nos anos de 2017, 2018 e 2019, respectivamente. Desta forma, o ginasta vem recebendo a bolsa de acordo com a sua posição internacional.

O atleta Arthur Nory recebeu a categoria Internacional do PBA nos anos de 2009, 2011 e 2012. No Evento Teste para os JO de Londres (GBR), em 2012, obteve a sua melhor colocação até então, o $12^{\circ}$ lugar no solo. Ainda em 2012, o atleta participou dos JO da Juventude, no qual conquistou o quarto lugar no aparelho salto. A partir de 2014, Arthur Nory recebeu de maneira interrupta a bolsa do PBAP, sendo que no ano anterior teve a sua primeira participação em CM. $\mathrm{Na}$ ocasião, o $17^{\circ}$ lugar individual geral garantiu a possibilidade do pleito ao PBAP. No ano seguinte, o $18^{\circ}$ lugar na barra fixa foi a melhor posição obtida. Já em 2015, o ginasta apresentou um salto em seus resultados ao finalizar o CM em quarto lugar na barra fixa, décimo lugar no solo e $12^{\circ}$ lugar individual geral. Como já dito anteriormente, o atleta alcançou a medalha olímpica em 2016, bronze na prova de solo, logo após ter sido contemplado pelo PBAP. Durante o ciclo olímpico 2017-2020, os melhores resultados de Arthur Nory em CMs foram: $12^{\circ}$ lugar na prova de barra fixa (2017), $27^{\circ}$ lugar no solo (2018), e campeão da barra fixa (2019).

Já o atleta Caio Souza foi contemplado pelo PBA desde 2008 sendo beneficiado com a bolsa da categoria nacional. A primeira participação do atleta em CM foi em $2014^{8}$. No ano seguinte, quando contemplado pela categoria Internacional, a sua melhor posição no referido campeonato foi o $34^{\circ}$ lugar individual geral. No ano de 2016, quando passou a receber a bolsa do PBAP, Caio Souza não representou a equipe brasileira nos JO do Rio de Janeiro (2016). Porém, o atleta esteve no principal campeonato do ano seguinte, no qual logrou as melhores

\footnotetext{
${ }^{8}$ Apesar de Caio Souza ter participado da equipe brasileira, a FIG (2014) não apresenta os resultados individuais do atleta.
} 
posições na competição individual geral ( $15^{\circ}$ lugar) e nas barras paralelas simétricas ( $19^{\circ}$ lugar). Tais resultados o qualificaram para o PBAP. Em 2018 e 2019, Caio Souza se manteve entre os 20 melhores ginastas do mundo na modalidade no individual geral e obteve as seguintes melhores colocações nos respectivos CMs: $8^{\circ}$ lugar no aparelho salto e $13^{\circ}$ lugar individual geral.

O primeiro sul-americano medalhista mundial da GAM, Diego Hypólito, inaugurou sua participação em CMs em 2002, que finalizou em quinto lugar no solo a prova de sua especialidade. No ano seguinte, no CM de Anaheim (EUA) em 2003, subiu uma posição no mesmo aparelho, porém não foi o representante brasileiro nos Jogos Olímpicos de Atenas, em 2004 (Hypólito, 2019). Na ocasião foi Mosiah Rodrigues quem representou o Brasil, atleta que conquistou a vaga individual no CM anterior. Em 2005, Diego Hypolito foi campeão mundial na disputa do solo e manteve-se no pódio no ano seguinte quando foi vice-campeão e, mais uma vez, campeão em 2007. Nos JO de Pequim, no ano de 2008, o ginasta teve uma queda na final olímpica e encerrou a competição em sexto lugar. Mantendo-se ativo no cenário internacional da GAM, Diego Hypólito retornou ao pódio em 2011 com a conquista do bronze no solo e $11^{\circ}$ no salto. Na segunda edição olímpica da sua carreira, na cidade de Londres em 2012, uma queda na etapa classificatória o deixou de fora da final olímpica de solo ( $59^{\circ}$ lugar). Já no ano seguinte o ginasta voltou a disputar a final do $\mathrm{CM}$ e conquistou o quinto lugar no solo e sexto no salto. A partir de 2011, Diego Hypólito passou a ser beneficiado pelo PBA. Vale destacar que anteriormente o PBA era destinado exclusivamente para atletas que não recebessem patrocínios privados e, por isso, alguns atletas não recebiam o benefício. Inicialmente ele recebeu por três anos consecutivos a categoria Olímpica. Em 2014, quando passou a receber o PBAP, o atleta conquistou a medalha de bronze no solo e terminou em $11^{\circ}$ lugar o salto no CM. No ano seguinte, Diego Hypólito não participou da principal competição daquele ano. Finalmente, em 2016, o atleta conquistou a então inédita medalha brasileira na prova de solo ao ficar com a prata. Entre os anos de 2017 e 2018, ele não participou de competições da FIG, no entanto, recebeu a categoria Olímpica do PBA em 2018. Já em 2019, o ginasta esteve presente em duas etapas de Copa do Mundo.

Em 2007, observou-se a primeira vez em que Francisco Barretto Jr. foi contemplado pelo PBA, no qual ingressou na categoria Internacional. A primeira participação do ginasta em CM ocorreu em 2010, quando obteve como melhor resultado naquele evento o $69^{\circ}$ lugar na barra fixa. $\mathrm{O}$ atleta voltou a participar do PBA sendo contemplado na categoria Internacional no período de 2011 e 2012. Em 2011, o atleta melhorou a sua posição no CM, na prova da barra 
fixa ao finalizar em $39^{\circ}$ lugar. Tendo em vista que o Brasil não conquistou a vaga por equipes para os JO de Londres, em 2012, e os resultados individuais do ginasta estavam aquém para a sua classificação, Francisco Barreto Jr. teve que postergar a sua aparição nesse megaevento esportivo. Nos três campeonatos mundiais seguintes, o ginasta oscilou entre o $22^{\circ}$ e $37^{\circ}$ lugar. Observa-se que, no contexto das competições analisadas nesse estudo, o melhor resultado do atleta foi no ano seguinte ao recebimento da bolsa do PBAP, nos JO do Rio de Janeiro, quando obteve o quinto lugar na barra fixa. No ano seguinte, o atleta participou de três etapas da Copa do Mundo. Na última etapa, realizada em Varna (Bulgária), Francisco Barretto Jr. sofreu uma lesão que o deixou fora do CM de 2017. Ainda assim, ressalta-se que o ginasta obteve resultados expressivos nas etapas de Copa do Mundo de 2017 e, naquele mesmo ano, retornou ao PBAP, bolsa que recebe até então. Francisco Barreto Jr. retornou ao CM em 2018, quando obteve o $11^{\circ}$ lugar na prova de cavalo com alças e $15^{\circ}$ lugar na barra fixa. No ano seguinte, finalizou a principal competição em $21^{\circ}$ lugar no cavalo com alças e contribui com a classificação olímpica da equipe brasileira.

O ginasta Henrique Flores não competiu em JO e/ou CM da modalidade. O atleta, especialista nas argolas, foi contemplado pelo PBA na categoria Internacional em 2013 e, na categoria Pódio, nos anos de 2015 e 2017. Entre os anos de 2015 e 2016 o atleta participou de três etapas da Copa do Mundo. Em 2015, Henrique Flores foi vice-campeão da etapa de São Paulo (Brasil), um feito que se repetiu na etapa de Cottbus (Alemanha) no ano seguinte, resultado que possivelmente tenha sido utilizado para pleitear o PBAP.

O atleta Petrix Barbosa recebeu a primeira bolsa do PBA em 2005 na categoria Estudantil. Durante os anos de 2006, 2007 e 2011 o atleta foi contemplado na categoria Nacional. Já nos anos de 2008 a 2014, exceto em 2011, o ginasta recebeu a bolsa Internacional.

Em 2012 participou do Evento Teste dos JO de Londres e a sua melhor posição individual foi o $25^{\circ}$ lugar no cavalo com alças. No entanto, a única participação de Petrix Barbosa em CM representando o Brasil ocorreu na cidade de Tóquio em 2011, quando o atleta obteve como melhores resultados o $52^{\circ}$ lugar no individual geral e na barra fixa. Nos anos de 2014 e 2015, o atleta participou de etapas da Copa do Mundo tendo como melhores resultados, respectivamente, segundo lugar na barra fixa e quarto lugar na prova de cavalo com alças. Em 2015, o ginasta foi contemplado pelo PBAP, possivelmente, amparado por tais resultados. Desde 2018, Petrix Barbosa representa a seleção portuguesa de GAM, inclusive participou dos CMs de 2018 e 2019, conquistando como melhor posição o $85^{\circ}$ lugar individual geral e o $56^{\circ}$ lugar nas argolas. 
Desde o início de sua carreira, Sérgio Sasaki Jr. foi contemplado cinco vezes pelo PBA. No ano de 2008, pela primeira vez foi apreciado com a bolsa Nacional. No ano seguinte teve sua primeira participação em CM, quando obteve o seu melhor resultado na competição individual geral com o $19^{\circ}$ lugar. Em 2010, a sua melhor colocação na mesma competição foi o $23^{\circ}$ lugar na prova de salto. Em 2011, quando passou a receber a bolsa Internacional e o melhor resultado do ginasta na mesma competição foi o $37^{\circ}$ lugar no individual geral. Nos JO de Londres (2012), Sérgio Sasaki Jr. finalizou a competição em décimo lugar no individual geral, a melhor colocação conquistada por brasileiros na prova. No CM do ano seguinte, com a bolsa Olímpica, o ginasta foi quinto lugar individual geral mundial e, também, repetiu a colocação no CM de 2014 na prova de salto. Desta forma, garantiu o recebimento do PBAP, o qual ocorreu nos anos de 2014 e 2015. Apesar de não ter participado do CM de 2015, o ginasta participou dos JO do Rio de Janeiro (2016), no qual finalizou em nono lugar na competição do individual geral. Desde então, Sérgio Sasaki Jr. não participou de competições internacionais, pois se aposentou.

\section{Discussão}

Partindo da hipótese inicial de que haveria certa perenidade dos atletas da GAM no PBA, buscou-se identificar, com base nos resultados esportivos desses atletas, se houve melhora no desempenho concomitantemente a uma escalada nas categorias de bolsa; ou se tornaram beneficiários apenas ao atingir as condições exigidas pelo PBAP.

Como foi possível observar, todos os ginastas brasileiros contemplados pelo PBAP (2014 - 2020) já haviam sido beneficiados por outra categoria do PBA. O que, de certa forma, afirma o êxito do PBA, afinal, demonstra que os ginastas já estavam sendo contemplados antes de chegarem ao alto rendimento. Ainda assim, é necessário lembrar que o PBA, como dito por Malagutti, Canan e Starepravo (2015), segue preceitos da meritocracia, ou seja, o atleta recebe a bolsa de acordo com os resultados por ele conquistados, seja em âmbito nacional ou internacional. Quanto melhor o resultado, maior o valor da bolsa concedida ao esportista. Tal fato foi constatado a partir dos dados aqui apresentados e corrobora com os achados de Vargas e Capraro (2020). Os autores destacaram que os atletas da GAM participantes de CM entre os anos de 2017 e 2019 entendem esse processo como um estímulo ao atleta, ou seja, ele se dedica mais aos treinos e competições para manter ou, até mesmo, subir de categoria dentro do PBA.

Ainda assim, em alguns casos, os atletas apresentaram oscilações da categoria de bolsa recebida, certamente acompanhando os resultados alcançados no período anterior, inclusive 
após o recebimento da categoria mais alta do PBA. De maneira símile, Oliveira, Vargas e Capraro (2020), ao analisarem as atletas de ginástica artística feminina contempladas pelo PBAP, identificaram variação nas categorias de bolsa recebidas por elas. Tal oscilação deve ser observada pois indica lacunas no PBA. Não deveria o atleta manter a categoria de bolsa ou, ainda, subir de categoria ao longo dos anos de treinamento, assim como observou-se no histórico de Caio Souza? Oliveira e Bortoleto (2012) explicam que tal descontinuidade pode ser atribuída à falta de resultados satisfatórios e a não participação em competições.

No entanto, é necessário refletir que atletas de elite estão sujeitos a lesões e a outras intercorrências que os fazem, por vezes, não conquistarem os melhores resultados em competições, ou, ainda, não participarem de eventos. Fato este que foi evidenciado pelo estudo de Vargas e Capraro (2020). Os ginastas entrevistados pelos autores indicaram a necessidade de o PBA usar outros indicadores para avaliar a elegibilidade do atleta. Nessa esteira, os autores destacaram que, ao considerar apenas os resultados individuais, o PBA menospreza atletas importantes da seleção nacional. Ginastas que completam a equipe desempenham um papel primordial para o resultado da equipe, pois, no caso da GAM, são formadas por cinco atletas e as três melhores notas por aparelho são consideradas. A GAM brasileira, por exemplo, conquistou nos últimos anos resultados expressivos nas disputas por equipes, a saber: sexto lugar nos JO do Rio de Janeiro (2016); sétimo lugar por equipe no CM de 2018; e décimo lugar na mesma competição de 2019. Sendo que esse último resultado, garantiu a vaga por equipes da GAM brasileira nos Jogos Olímpicos de Tóquio (Vargas, \& Capraro, 2020). Nesse sentido, pondera-se a necessidade de discutir os critérios de distribuição do PBA, considerando, inclusive, as especificidades dos esportes. Afinal, se é intento conquistar o maior número de medalhas olímpicas, seria necessário avaliar as reais chances de cada modalidade. Todavia, não é exatamente desta forma que o PBA funciona, o que é refletido nos dados utilizados nesta pesquisa.

Ainda assim, observou-se na presente pesquisa casos em que os atletas não haviam participado do campeonato principal da modalidade, mas foram contemplados pelo PBAP. Possivelmente, os ginastas respaldaram-se em resultados de copas do mundo e justificaram a não participação nas principais competições. Situação essa que é prevista pelo texto da lei, pois cabe à confederação esportiva indicar as competições válidas (Camargo \& Mezzadri, 2017), de certa forma, garantindo uma abertura para os casos omissos. A falta de documentos que possam esclarecer tais situações, como a não publicação das atas de reuniões que definem os contemplados, abre espaço para especulações. Por exemplo, quais os motivos da não 
participação no principal evento internacional da modalidade? O atleta sofreu alguma lesão no período? Foi uma decisão estratégica da comissão técnica? Tal dificuldade de acessar outras informações a respeito do PBA, para além das portarias e editais publicados na homepage do governo federal, também foi citada por Malagutti, Canan e Starepravo (2015). Os autores questionam inclusive a confiabilidade dos dados publicados.

Ao contrário desses casos em que os atletas contemplados não teriam participado da competição principal da modalidade, o atleta Diego Hypólito foi um dos ginastas brasileiros de grandes feitos internacionais que teve início tardio no PBA. Campeão mundial em 2005 e 2007, ingressou no PBA em 2011, possivelmente, conforme supracitado, pela impossibilidade de atletas patrocinados o pleitearem antes disso. Teixeira et al. (2017) indicam que mudanças ocorridas no PBA, por meio da Lei 12.395/2011, se deram para focalizar os investimentos no esporte de alto rendimento do país, direcionando maiores recursos para as modalidades olímpicas e paralímpicas, na tentativa de melhorar a posição do país no quadro de medalhas nas próximas edições do JO. Além disso, a realização dos JO em território nacional (2016) impulsionou ações com a intenção de projetar o esporte nacional (Dias, Moraes e Silva, Figuerôa, Rojo, \& Mezzadri, 2016; Silva, Silvestre, \& Silva, 2020). Pondera-se que, apesar da edição do Rio (2016) ter sido o melhor resultado brasileiro no quadro de medalhas, $13^{\circ}$ lugar geral, o país não alcançou o objetivo traçado (Silva, Silvestre, \& Silva, 2020).

Todavia, apenas dois entre os nove atletas analisados se destacam por se manter recebendo bolsas do PBAP por sete anos. São eles: Arthur Zanetti (2014 a 2020) e Arthur Nory (2014 a 2020). Ambos os ginastas fazem parte do seleto grupo de atletas contemplado pelo PBAP que alcançaram o objetivo primário: a medalha olímpica. Teixeira et al. (2017) indicam que somente $0,11 \%$ dos 46.246 atletas brasileiros bolsistas, no período por eles pesquisados, conquistaram medalhas nas edições olímpicas de Pequim (2008), Londres (2012) e Rio de Janeiro (2016). Sendo que Arthur Zanetti conquistou 2 medalhas, do total de 51 conquistadas por brasileiros. É importante destacar que os outros sete atletas listados nesta pesquisa não apresentaram perenidade na categoria do PBAP, todavia, apresentaram uma considerável constância como bolsistas do PBA, em outras categorias - como a Internacional e a Olímpica.

Posto isto, o financiamento do governo federal brasileiro possivelmente interferiu na performance esportiva desses ginastas. Conforme explica Oliveira e Bortoleto (2009), os recursos advindos da bolsa possibilitam o atleta permanecer mais tempo em treinamento, participar de treinamentos em outros países, ter acesso a aparelhagem moderna para os treinamentos e, também, viabilizam a participação em mais competições internacionais. Por se 
tratar de uma modalidade em que a avaliação é em parte subjetiva, quanto mais o ginasta participar de competições e treinamentos internacionais, maior será a visibilidade dele, podendo influenciar diretamente em sua nota na competição (Oliveira, Noé, \& Bortoleto, 2019). Além disso, Oliveira e Bortoleto (2012) identificaram que os bolsistas conseguem permanecer mais tempo treinando, tendo em vista que a bolsa supre, de certa forma, a necessidade de contribuir com a renda familiar.

Embora abordem a ginástica rítmica, Paz, Costa, Lourenço, Starepravo e Rinaldi (2018) constataram que o PBA contribui diretamente na manutenção e aprimoramento de ginastas da seleção da modalidade. As ginastas entrevistadas naquela pesquisa indicaram contribuições em dois aspectos: profissional e pessoal. No primeiro, elas indicaram a compra de materiais específicos da modalidade (collants, sapatilhas, aparelhos), suplementos alimentares e despesas em competições. No segundo, elas destacaram a estabilidade financeira, que possibilita a dedicação integral aos treinamentos. Na mesma direção, Oliveira e Bortoleto (2012) inferiram que o PBA é um fator de motivação para a manutenção do atleta em atividade, para além de auxiliar nos custeios de insumos da modalidade, os entrevistados indicaram que a bolsa muitas vezes é a maior fonte de renda de ginastas brasileiros. Por outro lado, Vargas e Capraro (2020) identificaram que os atletas da seleção brasileira de GAM recebem outros incentivos financeiros, especialmente depois de chegar ao alto rendimento da modalidade, chamando a atenção para a sobreposição de ações de incentivo ao esporte no Brasil ${ }^{9}$.

Vale destacar que o principal objetivo do PBAP é investir em atletas com reais chances de medalha olímpica. Neste sentindo, destaca-se que Arthur Nory, Arthur Zanetti e Diego Hypólito, os três medalhistas olímpicos da GAM em 2016, estavam recebendo o benefício do PBAP na ocasião. Desta forma, corroborando com os achados de Costa, Costa, Ordonhes, Zamboni e Cachiolli (2021), os quais identificaram que todos os medalhistas brasileiros nos JO do Rio de Janeiro estavam sendo apoiados pelo PBA. Além disso, os colegas representantes da equipe nacional, Francisco Barretto Jr. e Sérgio Sasaki Jr., os quais juntos conquistaram o inédito sexto lugar por equipe (FIG, 2016), também estavam recebendo o benefício do PBAP. Ao comparar com as ginastas do setor feminino, apenas três atletas da seleção brasileira recebiam bolsa do PBAP na ocasião, no entanto, tal fato foi justificado pelos critérios para o pleito (Oliveira, Vargas, \& Capraro, 2020).

\footnotetext{
${ }^{9}$ Na pesquisa de Santos (2018), ao tratar do caso específico dos atletas do boxe, identifica-se, por exemplo, que alguns atletas receberam bolsas do governo federal, do estadual e do municipal. Isso pode ser pensado como uma dessas sobreposições de ações; ou seja, o governo, em diferentes níveis, direcionando recursos públicos para a mesma finalidade.
} 
Acentua-se que a GAM foi a $19^{\mathrm{a}}$ modalidade masculina, entre os anos de 2005 e 2011, na quantidade de distribuição das diferentes bolsas do PBA (Corrêa et al., 2014). Porém, conforme é possível constatar no estudo de Teixeira et al. (2017), a modalidade foi a quinta que mais medalhou nos JO de Londres dentre os esportes individuais, ficando apenas atrás do judô (quatro medalhas), do boxe (três medalhas), da natação (duas medalhas) e do vôlei de praia (duas medalhas). Já nos JO do Rio de Janeiro, das 19 medalhas conquistadas por brasileiros, três foram da GAM (Silva, Silvestre, \& Silva, 2020). Tal comparação levanta indícios para questionar a efetividade da distribuição dos recursos do governo brasileiro para o esporte, a partir de seus objetivos já expostos. Afinal, tal modalidade parece ser mais rentável ao governo federal quando comparada com outras modalidades com número maior de beneficiados e menos medalhas conquistadas (Costa et al., 2021).

Outro ponto que se destaca é o fato de o PBAP se constituir como um benefício para o atleta que já está na etapa dos grandes resultados. Isso é evidenciado com base nos resultados apresentados por essa pesquisa, nos quais é possível perceber que, à exceção de Francisco Barreto Jr., os demais atletas entraram no PBAP após já apresentarem bons resultados em eventos proeminentes da modalidade. Isso permite entender que, ao ser contemplado na referida categoria, o esportista já atingiu a etapa de resultados superiores (Schiavon, Paes, Moreira, \& Maia, 2011). Ou seja, por meio de avaliação e da construção de um modelo lógico do PBA, pode-se hipotetizar que o PBAP auxilia o atleta a se manter entre os melhores do mundo.

\section{Considerações finais}

Ao apresentar os resultados internacionais dos ginastas brasileiros contemplados pelo PBAP, bem como o histórico do recebimento de bolsas de outras categorias do PBA recebidas ao longo da carreira esportiva, pode-se identificar que os atletas mantiveram certa perenidade enquanto beneficiários do PBA, em suas diferentes categorias, o que sinaliza uma regularidade de resultados satisfatórios para pleitear o benefício. No entanto, foi perceptível que, no caso de alguns ginastas, houve variações nas categorias da bolsa, o que indica inconstâncias nos resultados competitivos e, em alguns casos, a não participação em eventos competitivos que eram requisitos para se manter ou melhorar a categoria do auxílio recebido.

Apesar disso, os dados do estudo confirmam a plausibilidade da hipótese lançada no início do estudo de que esses auxílios financeiros são essenciais para o atleta permanecer no treinamento e nas competições, muito possivelmente, devido a questões de mercado. Tendo em 
vista a tendência da falta de lucratividade em torno de grande parte das modalidades no Brasil, tidas como não tradicionais (Almeida, Micaliski, \& Silva, 2019) e, portanto, não populares, conta-se com um baixo número de consumidores em potencial. Nesse sentido, destaca-se a centralidade dos recursos financeiros públicos para a manutenção desses atletas, por meio, sobretudo, do PBA. Ainda assim, é importante ressaltar que o recebimento do PBAP ocorre a partir da lógica meritocrática, pois é necessário que o atleta obtenha resultado expressivo para que seja contemplado com o benefício.

Ao finalizar a análise, destaca-se a necessidade de produzir pesquisas a partir de novas fontes que possam auxiliar nas reflexões a respeito das políticas públicas para o esporte no Brasil, tendo em vista que o referido PBA é o mais representativo no país. Desse modo, sugerem-se estudos futuros que utilizem de questionários e/ou entrevistas com os atletas e treinadores de diferentes modalidades no sentido de compreender as possíveis influências desta importante política pública para o esporte brasileiro na formação esportiva.

\section{Referências}

Almeida, B. S. de; Micaliski, E. L.; Silva, M. R. da. (2019). Esportes Complementares. Curitiba: InterSaberes.

Anunciação, F. N., Moraes, M., Maoski, A. P. C. B., Tagliari, C. C., Rojo, J. R., \& Mezzadri, F. M. (2017). O panorama do atletismo no Programa "Bolsa-atleta": uma análise entre os anos de 2011 a 2013. Caderno de Educação Física e Esporte, 15(2), 57-68.

Brasil. (2004). Lei no 10.891, de 9 de julho de 2004. Institui a Bolsa-Atleta. Disponível em: http://www.planalto.gov.br/ccivil_03/_Ato2004-2006/2004/Lei/L10.891.htm

Brasil. (2011). Lei ${ }^{\circ} 12.395$, de 16 de março de 2011. Altera as Leis $n^{\circ} .9 .6415$, de 24 de março de 1998, que institui normas gerais sobre desporto, e 10.891, de 9 de julho de 2004, que institui a Bolsa-Atleta; cria os Programas Atleta Pódio e Cidade Esportiva, revoga a Lei $n^{\circ}$. 6.354, de 2 de setembro de 1976; e dá outras providências. Disponível em: http://www.planalto.gov.br/ccivil_03/_Ato2011-2014/2011/Lei/L12395.htm

Brasil. (2017). Portaria/ME n⿳ 76, de 15 de março de 2017. Altera a Portaria $n^{\circ}$ 67, de 4 de abril de 2013, que estabelece procedimentos para seleção de atletas no âmbito do Programa Atleta Pódio, assim como estabelece modelos e critérios gerais para a elaboração do Plano Esportivo, ambos instituídos pela Lei n 12.395 , de 2011. Disponível em:http://www.lex.com.br/legis_27336954_PORTARIA_N_76_DE_15_DE_MARCO _DE_2017.aspx 
Brouwers, J., Sotiriadou, P., \& De Bosscher, V. (2015). Sport-specific policies and factors that influence international success: The case of tennis. Sport Management Review, 18(3), 343-358. https://doi.org/10.1016/j.smr.2014.10.003

Camargo, P. R. de. (2020). O programa Bolsa-atleta: desenvolvimento da performance esportiva e política de Welfare State. Tese (doutorado) - Universidade Federal do Paraná, Setor de Ciências Biológicas. Programa de Pós-Graduação em Educação Física.

Camargo, P. R. de, Santos, T. de O., Oliveira, A. P. V. de, Quaranta, A. M., \& Mezzadri, F. M. (2020). Public funding for Paralympic athletes in Brazil: does the "Bolsa-Atleta" Program encourage the permanence and improve sport results?. Research, Society and Development, 9(12), e18691210970. https://doi.org/10.33448/rsd-v9i12.10970

Camargo, P. R., \& Mezzadri, F.M. (2017). Políticas públicas para o esporte: o programa Bolsa-Atleta e sua abrangência na base do handebol no Brasil. Pensar a Prática 20(1). https://doi.org/10.5216/rpp.v20i1.39927

Canan, F., Starepravo, F. A., \& de Athayde, P. F. A. (2017). A pesquisa aplicada na temática de políticas públicas de esporte e lazer no Brasil. Caderno de Educação Física e Esporte, 15(2), 11-14.

Cavill, N., Foster, C., Oja, P., \& Martin, B. W. (2006). An evidence-based approach to physical activity promotion and policy development in Europe: contrasting case studies. Promotion \& education, 13(2), 104-111. https://doi.org/10.1177/10253823060130020104

Chen, S. (2018). Sport policy evaluation: what do we know and how might we move forward? International Journal of Sport Policy and Politics 10(4) 1-19. https://doi.org/10.1080/19406940.2018.1488759

Coalter, F. (2017). Sport and Social Inclusion: Evidence-Based Policy and Practice. Social Inclusion 5(2) 141-149. https://doi.org /10.17645/si.v5i2.852

Corrêa, A. J., Moraes, M., Mezzadri, F. M., \& Cavichiolli, F. R. (2014). Financiamento do esporte olímpico de verão brasileiro: mapeamento inicial do programa "Bolsa-atleta" (2005-2011). Pensar a prática, 17(4). https://doi.org/10.5216/rpp.v17i4.29057

Costa, I. P., Costa, C., Ordonhes, M. T., Zamboni, K. J., \& Cavichiolli, F. R. (2021). O programa brasileiro Bolsa-Atleta: relações entre o investimento e os resultados esportivos entre 2005-2016. Research, Society and Development, 10(3), e10910312699-e10910312699. https://doi.org/10.33448/rsd-v10i3.12699

Diário Oficial da União. (2021). Imprensa Nacional do Brasil. Disponível em: http://www.in.gov.br/consulta.

Dias, Y. R., Moraes, M., Figuerôa, K. M., Rojo, J. R., \& Mezzadri, F. M. (2016). O panorama do judô no programa" Bolsa-Atleta": uma análise entre os anos de 2011 a 
2013. Motrivivência, 28(49), 82-98. https://doi.org/10.5007/2175-

8042.2016v28n49p82

Dye, T. (1972). Understanding public policy. Englewwod Cliffs, NJ: Prentice-Hall.

Federação Internacional de Ginástica (2016). Results for Games of the XXXI Olimpiad Rio de Janeiro. Disponível em:

https://www.gymnastics.sport/site/events/results.php?idEvent=6405

Frey, K. (2009). Políticas públicas: um debate conceitual e reflexões referentes à prática da análise de políticas públicas no Brasil. Planejamento e políticas públicas, (21).

Funnell, S. C., \& Rogers, P. J. (2011). Purposeful program theory: Effective use of theories of change and logic models (Vol. 31). John Wiley \& Sons.

Gertler, P. J., Martinez, S., Premand, P., \& Rawlings, L. B. (2018). Avaliação de Impacto na Prática, $2^{\mathrm{a}}$ edição. World Bank Publications.

Godoy, L. (2013). O sistema nacional de esporte no Brasil: revelações e possíveis delineamentos. Tese (doutorado) - Universidade Federal do Paraná, Setor de Ciências Biológicas. Programa de Pós-Graduação em Educação Física.

Hypolito, D. (2019). Não existe vitória sem sacrifício: da depressão severa à medalha Olímpica, a trajetória de superação do mais vitorioso ginasta brasileiro / Diego Hypolito em depoimento a Fernanda Thedim. São Paulo: Benvirá.

Lindsey, I., \& Bacon, D. (2016). In pursuit of evidence-based policy and practice: A realist synthesis-inspired examination of youth sport and physical activity initiatives in England (2002-2010). International Journal of Sport Policy and Politics, 8(1), 67-90. https://doi.org/10.1080/19406940.2015.1063528

Malagutti, J. P. M., Canan, F., \& Starepravo, F. A. (2015). La bolsa de atletas y el desenvolvimiento del deporte olímpico brasileño. Impetus, 9(1), 89-95. http://doi.org/10.22579/20114680.133

Martinson, K., \& O’brien, C. (2015). Conducting Case Studies. In: Newcomer, K. E.; Hatry, H. P.; Wholey, J. S. Handbook of Practical Program Evaluation. Hoboken: John Wiley \& Sons (4) 177-196.

Mezzadri, F. M., Moraes e Silva, M., Figuêroa, K. M., \& Starepravo, F. A. (2015). Sport policies in Brazil. International Journal of Sport policy and politics, 7(4), 655-666. https://doi.org/10.1080/19406940.2014.937737

Moraes, M., Mezzadri, F. M., Santos, N., de Camargo, P. R., \& Figuerôa, K. M. (2015). La configuración de la ordenación legal relacionada a la financiación del gobierno brasileño hacia el deporte de elite: un análisis a partir de la Teoría de los Juegos de Norbert Elias. Lúdica Pedagógica, (21). https://doi.org/10.17227/01214128.21ludica77.89 
Moraes, M., Mezzadri, F. M., Figueroa, K. M., \& Starepravo, F. A. (2016). El panorama de las políticas públicas del deporte en Brasil. Revista observatorio del deporte, 163-188.

Oliveira, M.E. de, Vargas, P.P.I., \& Capraro, AM. (2020). Análise da carreira esportiva das atletas contempladas pela Bolsa Atleta Pódio na ginástica artística feminina. Lecturas: Educación Física y Deportes, 25(269), 60-78. https://doi.org/10.46642/efd.v25i269.1822

Oliveira, M.S., \& Bortoleto, M.A.C. (2009). A ginástica artística masculina brasileira no panorama mundial competitivo (1987-2008). Motriz. Journal of Physical Education. UNESP 297-309. https://doi.org/10.5016/2372

Oliveira, M.S., \& Bortoleto, M.A.C. (2012). Public sports policy: the impact of the athlete scholarship program on Brazilian men's artistic gymnastics. Science of Gymnastics Journal 4(1).

Oliveira, M.S. et al. (2019). A arbitragem na ginástica artística masculina do Brasil segundo a perspectiva de seus protagonistas. Revista Brasileira de Ciência e Movimento, 27(4) 73-84.

Ordonhes, M.T. et al. (2016). Possíveis relações entre investimentos públicos e obtenção de resultados: o caso da natação brasileira. Motrivivência, 28(47) 82-95. https://doi.org/10.5007/2175-8042.2016v28n47p82

Pawson, R. (2006). Evidence-Based Policy: A Realist Perspective. Londres: Sage Publications.

Paz, B., Costa, C. R., Lourenço, M. R. A., Starepravo, F. A., \& Rinaldi, I. P. B. (2018). A influência do programa bolsa-atleta na trajetória profissional e pessoal de atletas de ginástica rítmica. Motrivivência, 30(54), 127-142. https://doi.org/10.5007/21758042.2018v30n54p127

Reis, F. D. G., \& Capraro, A. M. (2020). Judocas brasileiros: um panorama sobre os atletas contemplados pelo programa bolsa-atleta pódio entre os anos de 2013 e 2018. Motrivivência, 32(63), 01-18. https://doi.org/10.5007/2175-8042.2020e72017

Santos, S. C. dos. (2018). Lutando dentro e fora do ringue: a perspectiva dos atletas e gestores do boxe olímpico sobre o Programa Bolsa-Atleta no ciclo olímpico Rio 2016. Dissertação (Mestrado) - Universidade Federal do Paraná, Setor de Ciências Biológicas. Programa de Pós-Graduação em Educação Física.

Schiavon, L.M. (2009). Ginastica artística feminina e história oral: a formação desportiva de ginastas brasileiras participantes de Jogos Olímpicos (1980-2004). Tese de doutorado. Universidade Estadual de Campinas, Faculdade de Educação Física, Campinas, SP. Disponível em: http://www.repositorio.unicamp.br/handle/REPOSIP/

Schiavon, L. M., Paes, R. R., Moreira, A., \& Maia, G. B. M. (2011). Etapas e volume de treinamento das ginastas brasileiras participantes de Jogos Olímpicos (19802004). Motricidade, 7(4), 15-26. https://doi.org/10.6063/motricidade.81 
Silva, D. S., Silvestre, B. M., \& Silva, J. V. P. D. (2020). Avaliação de políticas públicas de esporte: o caso do Plano Brasil Medalhas 2016. Revista Brasileira de Ciências do Esporte, 42. https://doi.org/10.1590/rbce.42.2019.075

Silva, D. S., Silvestre, B. M., \& Amaral, S. C. F. (2020). A avaliação da loteria timemania como política pública de esporte. Journal of Physical Education, 31. https: //doi.org/ 10.4025/jphyseduc.v31i1.3131

Secretaria Nacional de Esporte de Alto rendimento - SNEAR. (2021). Disponível em: https://www.gov.br/cidadania/pt-br/composicao/orgaos-especificos/esporte/SNEAR.

Starepravo, F. A. (2011). Políticas públicas de esporte e lazer no Brasil: aproximações, intersecções, rupturas e distanciamentos entre os subcampos político/burocrático e científico/acadêmico. Tese (doutorado) - Universidade Federal do Paraná, Setor de Ciências Biológicas. Programa de Pós-Graduação em Educação Física.

Stufflebeam, Daniel L., \& Coryn, Chris. L. S. (2014). Evaluation theory, models, and applications (2nd ed.). New Jersey: Jossey-Bass.

Teixeira, M. R., Matias, W. B., Carneiro, F. H., \& Mascarenhas, F. A. (2017). O Programa Bolsa Atleta no contexto esportivo nacional. Motrivivência, 29, 92-109. https://doi.org/10.5007/2175-8042.2017v29nespp92

Vargas, P. I., \& Capraro, A. M. (2020). Financial support in the sports trajectory of athletes of the brazilian selection of artistic gymnastics. Research, Society and Development, 9(10), e6969109089. https://doi.org/10.33448/rsd-v9i10.9089

Wholey, Joseph S. (2015). Exploratory Evaluation. In: Newcomer, K. E., Hatry, H. P., Wholey, J. S. Handbook of Practical Program Evaluation. 4th Edition. Hoboken: John Wiley \& Sons 88-107. 